\title{
Flexural Behaviour of Precast Steel Fibres Reinforces Concrete Composite Slabs with Different Shapes
}

\author{
Bin Luo
}

Lanzhou University of Technology, Lanzhou 730050, China

Corresponding Author Email: luobin@lut.edu.cn

https://doi.org/10.18280/acsm.440307

Received: 17 February 2020

Accepted: 30 May 2020

\section{Keywords:}

precast, concrete composite slab (CCS), failure mode, ultimate bearing capacity, calculation method

\begin{abstract}
This paper aims to disclose the flexural behaviours of concrete composite slabs (CCSs) with different materials and shapes. For this purpose, eight types of CCSs were prepared with three kinds of materials (i.e. natural concrete, steel fibre-reinforced slit ceramic aggregate concrete (SFRSCAC) and steel fibre-reinforced recycled aggregate concrete (SFRRAC)) and five different shapes (i.e. rough surface, rectangular-rib, cross-rib, bar truss and bar truss with rectangular-rib). Thus, eight full-size CCS were established and subjected to static load tests. Then, the load-deflection curves, load-rebar strain curves, load-concrete strain curves and strain-depth relationship were analysed in details. Finally, the calculation methods were proposed for the cracking and ultimate bending moments of the CCS. The results show that: (i) under the vertical load, the eight specimens shared similar flexural behaviours and all underwent the elastic phase, elasticplastic phase and failure phase; (ii) the crack resistance of both SFRSCAC and SFRRAC were greatly improved through the addition of steel fibres; (iii) the shape of the bottom plate has a major impact on the flexural performance of the CCS, especially in the elasticplastic phase and the failure phase; (iv) the effect of the bottom plate should be considered in the calculation of the cracking moment, and the contribution of steel fibres to the tensile zone should be taken into account for the calculation of ultimate bending moments of the CCSs fabricated by SFRSCAC or SFRRAC.
\end{abstract}

\section{INTRODUCTION}

Prefabrication technology represents the shift toward labour-saving, energy-efficient and low-carbon construction $[1,2]$. Such as US [3] is "modular housing", European countries [4] are "off-site production", and Malaysia [5] is "industrialized building". One of the most important components of prefabrication technology is composite slab which has been widely applied in residential construction, as it is easy to assemble, fast to produce and quick to construct $[6,7]$.

Moreover, much research has been done on the design, production and construction of the composite slabs. Especially Many more a large number of different type or various new materials of composite slabs have been created by scholars all over the world. For example, Daniels and Crisinel [8, 9] developed a calculation method for both single-span and multi-span composite slabs with ribbed decking for steelframed buildings, and demonstrated that the slab performance hinges on the decking, the composite slab (including additional reinforcement) and the interaction between the two components. Girhammar and Pajari [10] resulted that the tensile strength was higher for the fibres reinforced concrete topping through test with cast-in-site concrete topping on the shear capacity of hollow core slabs which was commonly used as load-bearing floors and roofs. Thanoon et al. [11] presents a ferrocement-brick composite slab which consists of ferrocement layer, bricks and mortar. Zhang et al. [12] presents a prediction approach for the failure mode and ultimate bearing capacity of the composite slab with inverted T-shaped precast ribbed bottom panel. Mansour at el. [13] investigated the flexural behaviour of a composite slab with a steel fibre concrete topping, and proved that the flexural behaviour is affected by both the steel fibre and interface roughness. Mohamad at el. [14] carried out bend tests on concrete sandwich precast slab which consist of outer layers made from RAC and polystyrene was used as the insulation core material. Tang et al. [15] studied steel faced sandwich composite panels in which phenolic foam was used as core in order to stronger fire resistance properties in residential building and cold-storage buildings.

Despite the above studies in different periods promote the development of Prefabrication technology, there are still some problems concerning the composite slab in China. For one thing, since China's civil construction industry is still dominated by concrete materials, concrete composite slabs (CCS)s are mainly components of prefabrication technology; for the other, A viable solution to these problems lies in the recycling of the huge amount of construction wastes produced annually in China. Through the recycling of construction wastes, it is possible to produce recycled aggregate concrete from recycled aggregates instead of natural aggregates, and apply it in the industrial production of precast concrete structure components like the CCS. This approach will relieve the depletion of natural aggregate resources, reduce the pollution from construction wastes, and go with the trend of construction industrialization and green building.

In previous studies, our research groups have introduced 
steel fibres into recycled aggregate concrete to enhance the apparent density, reduce internal microcracks and lower the crush index $[16,17]$, creating the steel fibre-reinforced slit ceramic aggregate concrete (SFRSCAC) and steel fibrereinforced recycled aggregate concrete (SFRRAC) [18, 19], and proved that the steel fibres can effectively prevent the microcrack development and improve the mechanical performance of recycled aggregate concrete.

To disclose the flexural behaviours of CCSs with different materials and shapes, eight types of CCSs were prepared with three kinds of materials (i.e. natural concrete, SFRSCAC and SFRRAC) and five different shapes (i.e. rough surface, rectangular-rib, cross-rib, bar truss and bar truss with rectangular-rib). Thus, eight full-size CCS models were established and subjected to static load tests. Then, the loaddeflection curves, load-rebar strain curves, load-concrete strain curves and strain-depth relationship were analysed in details. Finally, the calculation methods were proposed for the cracking and ultimate bending moments of the CCS. The findings shed new light on the future research and application of the CCS.

\section{EXPERIMENTAL PROGRAM}

\subsection{Details of specimens}

A total of eight one-way CCS specimens were designed and labelled as S1 S8. The dimensions and parameters of these specimens are given in Table 1 and Figure 1. For S1 and S2 (control specimens), both the bottom panel and concrete topping are made of natural concrete; For S3 S5, the bottom panel is made of SFRSCAC, while the concrete topping is made of natural concrete; For $\mathrm{S} 6 \sim \mathrm{S} 8$, the bottom panel is made of SFRRAC, while the concrete topping is made of natural concrete. The strength grade of the natural concrete used in our research is C30 [20].

Table 1. Basic parameters of specimens

\begin{tabular}{|c|c|c|c|c|}
\hline \multirow{2}{*}{ No. } & \multicolumn{2}{|c|}{ Precast bottom panel } & \multirow{2}{*}{$\begin{array}{l}\text { Material of cast-in-site } \\
\text { concrete topping }\end{array}$} & \multirow{2}{*}{$\begin{array}{c}L \times W \times t_{\mathrm{b}} \times t_{\mathrm{t}} \\
(\mathrm{mm} \times \mathrm{mm} \times \mathrm{mm} \times \mathrm{mm})\end{array}$} \\
\hline & Type of shape & Kind of material & & \\
\hline S1 & rectangular-rib & natural concrete & \multirow{8}{*}{ natural concrete } & \multirow{8}{*}{$3000 \times 900 \times 60 \times 60$} \\
\hline $\mathrm{S} 2$ & steel bar truss & natural concrete & & \\
\hline S3 & rough surface & SFRSCAC & & \\
\hline S4 & rectangular-rib & SFRSCAC & & \\
\hline S5 & cross-rib & SFRSCAC & & \\
\hline S6 & rectangular-rib & SFRRAC & & \\
\hline S7 & steel bar truss & SFRRAC & & \\
\hline S8 & steel bar truss with rectangular-rib & SFRRAC & & \\
\hline
\end{tabular}

Note: 1 . the rib height was $30 \mathrm{~mm}$ and the rib width was $200 \mathrm{~mm}$ in rectangular-rib and cross-rib;

2. $L$ : span of specimen, $W$ : width of specimen, $t_{\mathrm{b}}$ : thickness of precast panel, $t_{\mathrm{t}}$ thickness of cast-in-site concrete topping.

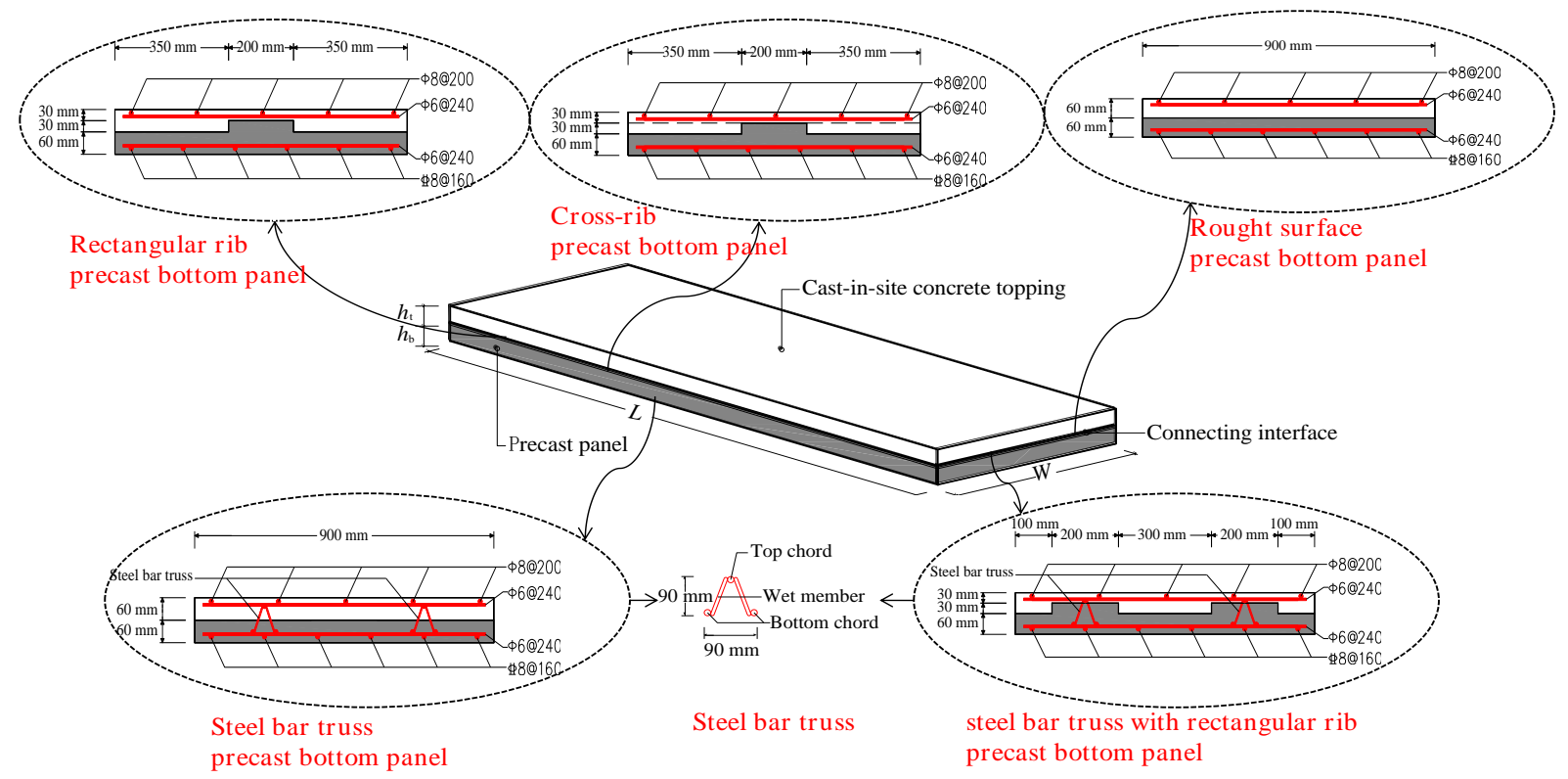

Figure 1. The structure and reinforcements of the specimens

In addition, A90 bars were adopted for S2, S7 and S8 according to the Chinese specification [21] "Technical specification for precast concrete structures": $8 \mathrm{~mm}$-diameter hot rolled ribbed bars for top and bottom chords and $6 \mathrm{~mm}-$ diameter hot rolled plain bars for web member. For all specimens, the longitudinal load-bearing bars are $8 \mathrm{~mm}$ diameter hot rolled ribbed bars arranged at an interval of 160mm (8@160). Meanwhile, 8mm-diameter hot rolled plan bars were arranged on the concrete topping at an interval of 200mm (8@200) to prevent cracking during hoisting. Moreover, the transverse bars of each specimen are $6 \mathrm{~mm}$ diameter hot rolled plain bars arranged at an interval of 240mm(6@240). 


\subsection{Materials}

The SFRSCAC [22] is a ceramic aggregate produced from the coarse aggregate of urban underground silt (replacement rate: $100 \%$ ), the fine aggregate of natural sand and $1 \%$ of steel fibres. For the coarse aggregate, the water absorption rate is $14.7 \%$, the crush index is $38.5 \%$ and the bulk density is $886 \mathrm{~kg} / \mathrm{m}^{3}$. The SFRRAC [23] is a recycled aggregate concrete produced from the coarse aggregate of crushed and screened waste concrete (replacement rate: 100\%), the fine aggregate of natural sand and $1 \%$ of steel fibres. For the coarse aggregate, the water absorption rate is $6 \%$, the crush index is $19 \%$ and the bulk density is $1013 \mathrm{~kg} / \mathrm{m}^{3}$. Steel fibres

Cubes (side length: 150mm) and prisms $(\mathrm{L} \times \mathrm{W} \times \mathrm{H}$ : $150 \times 150 \times 300 \mathrm{~mm}$ ) were prepared for each specimen to derive the mean cubic compressive, splitting tensile and axial compressive strength (Table 2). The specimens were curbed in a water bath at $20^{\circ} \mathrm{C} \pm 2^{\circ} \mathrm{C}$ for 28 days before testing.

Shear cut type steel fibres (length: $35 \mathrm{~mm}$; diameter:
$0.56 \mathrm{~mm}$; tensile strength: $2300 \mathrm{MPa}$ ) were adopted for our research and were shown in Figure 2. The arrangement of bars is explained in Section 2.1 and their mechanical properties are shown in Table 3.

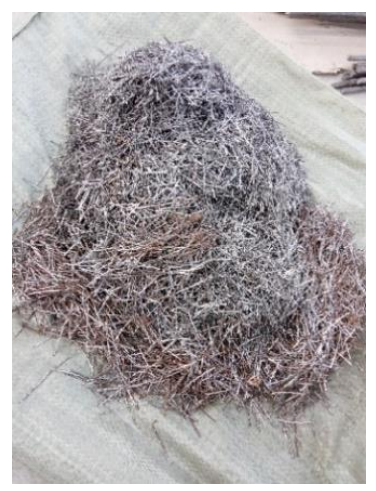

Figure 2. Steel fibre

Table 2. Mechanical properties of concretes

\begin{tabular}{clcccc}
\hline Material & Position & $\begin{array}{c}\text { Cubic compressive } \\
\text { strength }\left(\boldsymbol{f}_{\text {cu or }} \boldsymbol{f}_{\text {fcu }}\right) / \mathbf{M P a}\end{array}$ & $\begin{array}{c}\text { Axial compressive } \\
\text { strength }\left(\boldsymbol{f}_{\mathbf{c}}\right) / \mathbf{M P a}\end{array}$ & $\begin{array}{c}\text { Splitting tensile } \\
\text { strength }\left(\boldsymbol{f}_{\text {ts }}\right) / \mathbf{M P a}\end{array}$ & $\begin{array}{c}\text { Elastic } \\
\text { modulus } / \mathbf{M P a}\end{array}$ \\
\hline natural concrete & Precast bottom panel & 33.91 & 26.11 & 3.12 & $3.10 \times 10^{4}$ \\
SFRSCAC & Precast bottom panel & 32.42 & 21.74 & 2.91 & $3.06 \times 10^{4}$ \\
SFRRAC & Precast bottom panel & 37.54 & 30.53 & 3.98 & $3.20 \times 10^{4}$ \\
natural concrete cast-in-site concrete topping & 35.81 & 27.29 & 3.31 & $3.16 \times 10^{4}$ \\
\hline \hline SCAC & & 25.83 & 20.11 & 2.11 & $2.82 \times 10^{4}$ \\
RAC & & 31.14 & 23.95 & 2.42 & $3.02 \times 10^{4}$ \\
\hline
\end{tabular}

Note: 1 . The test blocks of slit ceramic aggregate concrete (SCAC) and recycled aggregate concrete (RAC) are tested to obtain the performance parameters of their matrix concrete, so that the calculation needs of the 4.1 chapter (detailed explanation in the 4.1 section);

2. The mixing ratio of SCAC and RAC is the same as SFRSCAC and SFRRAC, respectively, but the steel fibre was not blended.

Table 3. Mechanical properties of reinforcement

\begin{tabular}{cccc}
\hline Type and diameter/ mm & Yield strength/ MPa & Ultimate strength/ MPa & Elastic modulus/ MPa \\
\hline 6 & 300 & 429 & $2.1 \times 10^{5}$ \\
8 & 310 & 447 & $2.1 \times 10^{5}$ \\
8 & 434 & 570 & $2.0 \times 10^{5}$ \\
\hline
\end{tabular}

\subsection{Fabrication process of specimens}

Each specimen was fabricated in two phases, namely, the pre-casting of the bottom panel and the in-situ casting of the concrete topping. As shown in Figure 3, the bottom panel was produced in four steps: (i) clean and fix the steel structure mould (Figure 3(a)); (ii) place the bars of the bottom panel; (iii) fix the mould of rectangular-rib or cross-rib mould, if any (Figure 3(b)); (iv) prepare materials and pour concrete (Figure 3(c)). According to the Chinese code (GB 50010-2010), the top of the bottom panel was roughened after the coagulation of the concrete (Figure 3(d)). Then concrete topping was fabricated in three steps when the concrete strength of the bottom panel reached 75\%: (1) fix the mould on the bottom panel; (2) place the transverse bars of the concrete topping (Figure 3(e); (3) prepare materials and pour concrete (Figure 2(f)).

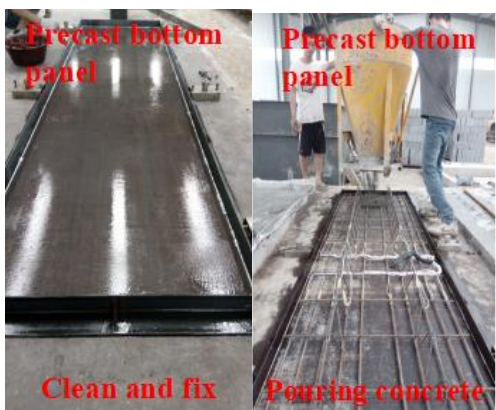

(a)

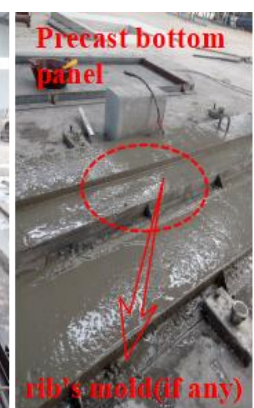

(c)

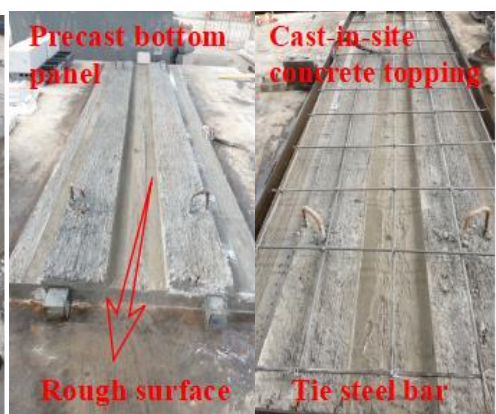

(d) (e)

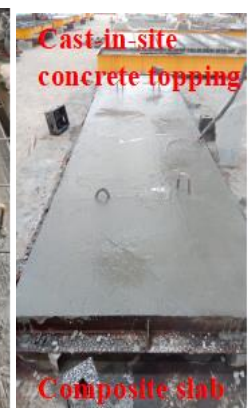

(f)

Figure 3. Photo construction procedure of specimens 


\subsection{Test set-up and loading procedure}

All specimens were tested on an electro hydraulic servo tester with a maximum capacity of $5,000 \mathrm{kN}$. During the tests, the specimens were subjected to four-point bending. Static loading was applied at the loading point by the electro hydraulic servo-controlled jacks and two linear loads were imposed on the specimens through a rigid transfer girder (Figure 4).

According to the Chinese standard [24] "Test method of concrete structures", the loading process was divided into preloading and formal loading. In pre-loading, there were three loading phases and three unloading phases, each of which has a load increment of $2 \mathrm{kN}$. In formal loading, the load increment was initially $2 \mathrm{kN}$ per phase, adjusted to $4 \mathrm{kN}$ per phase after the cracking of the specimen, and changed back to $2 \mathrm{kN}$ per phase when the load reached $90 \%$ of the calculated ultimate bearing capacity. After each load increment, midspan deflections, strains and crack propagation patterns were recorded for future discussion.

The load at load bearing capacity refers to the load measured in one of the following conditions: the midspan deflection reaches $1 / 50$ of the full span, the crack width of the main tensile bar widens to $1.50 \mathrm{~mm}$, the strain of the longitudinal load-bearing bar stands at 0.01 , and the longitudinal load-bearing bar is broken or the concrete topping is crushed in the compressive zone [24].

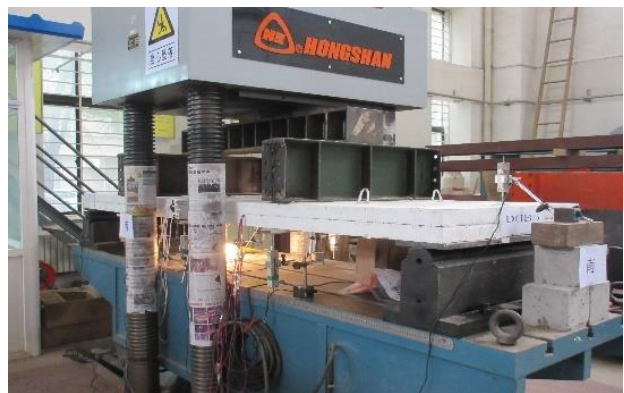

(a) Typical test photograph

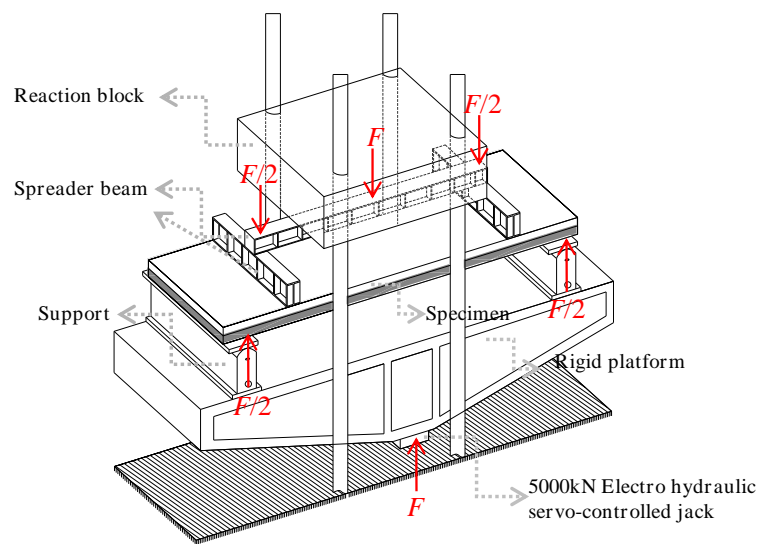

(b) Test devices

Figure 4. Test setup

\subsection{Measurements}

As shown in Figure 4(a), several linear variable displacement transducers (LVDTs) were adopted to measure the bending deflection of the specimens. The compressive/tensile strain of concrete were captured by electrical resistance stain gauges on the upper/lower surface and sides of the specimens (Figure 5(a)). Moreover, the bar strains were monitored by electrical resistance stain gauges on the bars serving as longitudinal load-bearing bars (Figure 5(b)), the upper/lower chords or web of bar truss (only for S2, S7 and S8) (Figure 5(c)).

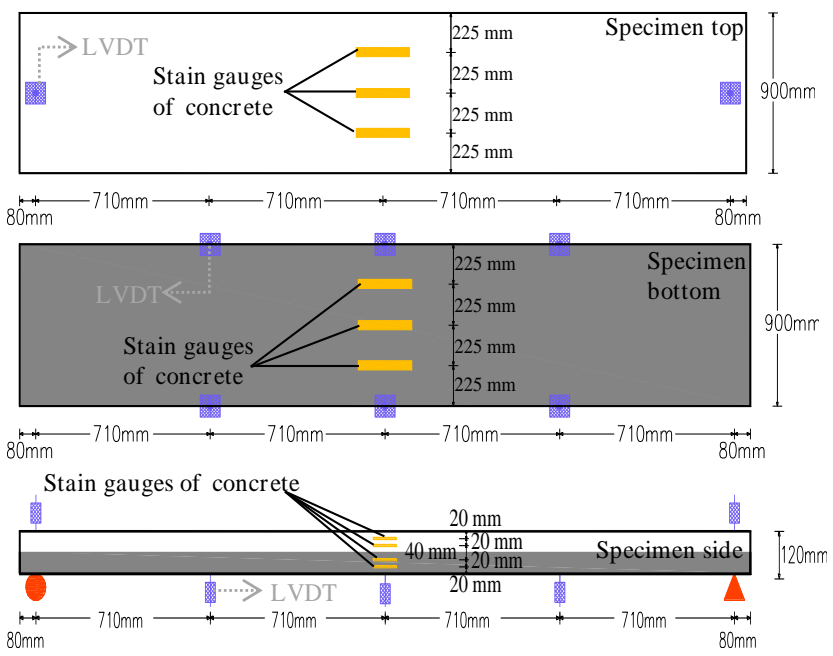

(a) Strain of concrete and LVDTs

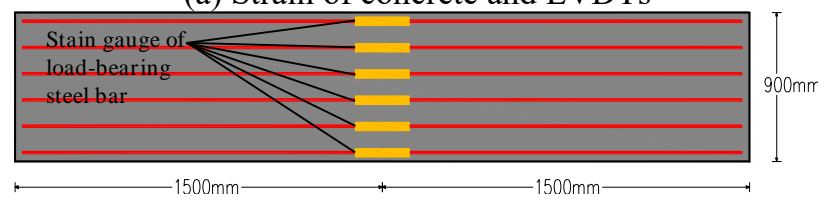

(b) Strain of bar

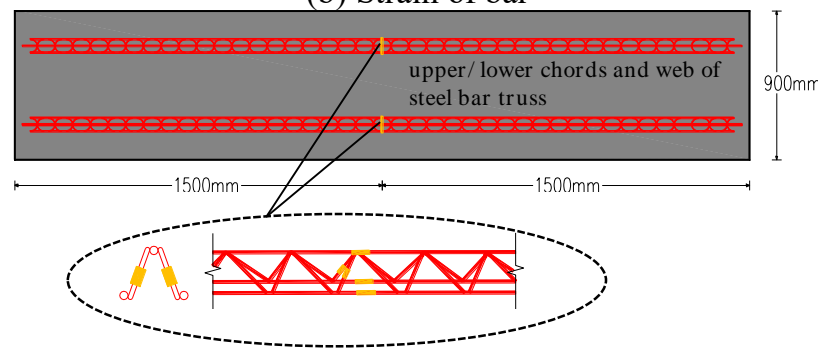

(c) Strain of bar truss

Figure 5. Test layout

\subsection{Characteristic load determination method}

The cracking load was determined in three ways: First, when the first crack appears in the loading process, the corresponding load should be taken as the cracking load; Second, when the first crack appears in a specific loading phase, the mean load between the current phase and the previous phase should be taken as the cracking load; Third, when the first crack appears after a specific loading phase, the current load should be taken as the cracking load [24].

The yield load of a member was determined by the farthest point method [25], that is, the yield load of a member should be measured at the yield point whose tangent slope is the same with the connecting line between the origin and the ultimate load point. The detailed explanation is shown in Figure 6 and formula (1). Where, $(F, D)$ is the component of forcedeformation curve, $\left(F_{\mathrm{ys}}, D_{\mathrm{ys}}\right)$ is the yield point coordinate determined by the farthest point method; $\left(F_{\mathrm{p}}, D_{\mathrm{p}}\right)$ is the peak point coordinates and $0 \leq D \leq D_{\mathrm{p}}$.

$$
\left(F_{\mathrm{ys}}, D_{\mathrm{ys}}\right)=\max _{\left(F_{\mathrm{y} s}, D_{\mathrm{y} s}\right)=(F, D)} d=\frac{\left|F_{\mathrm{p}} \times D-D_{\mathrm{p}} \times F\right|}{\sqrt{F_{\mathrm{P}}^{2}+D_{\mathrm{P}}^{2}}}
$$




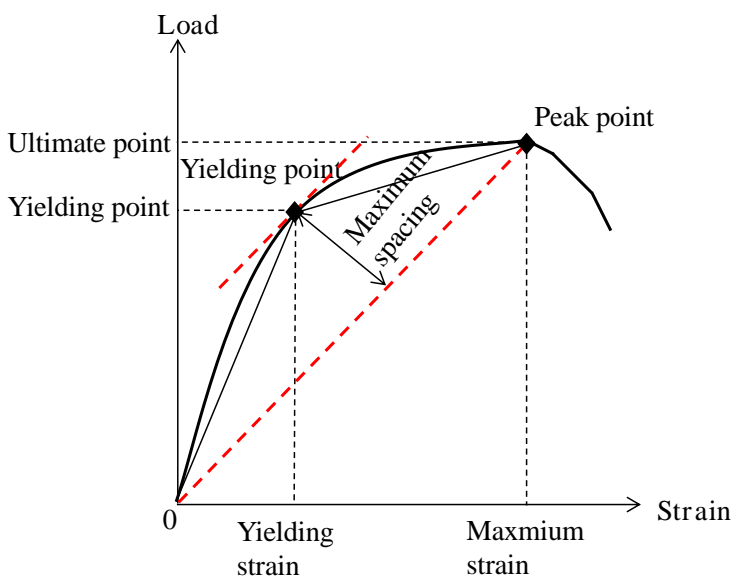

Figure 6. Proposed method to determine yielding point

\section{TEST RESULTS AND DISCUSSION}

\subsection{Failure modes}

Figure 7 illustrates the failure patterns of the specimens and Table 4 provides the failure features. Comparing the failure processes of the eight specimens, the following phenomena can be observed:

(i) Different phases of the loading process: Under the external load, all specimens went through the elastic phase, the elastic-plastic phase and the failure phase, and exhibited the typical features of bending failure in the end, indicating good ductility and bearing capacity. It is note that all the specimens did not slip along the overlapping surface between the precast bottom panel and cast-in-site concrete topping during the whole loading process (as shown in Figure 8, only CS-3 as an example).
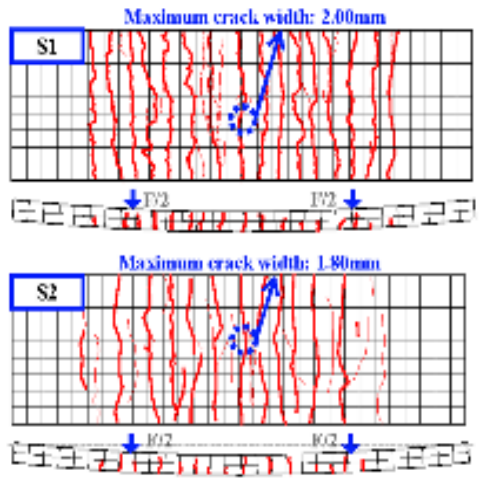
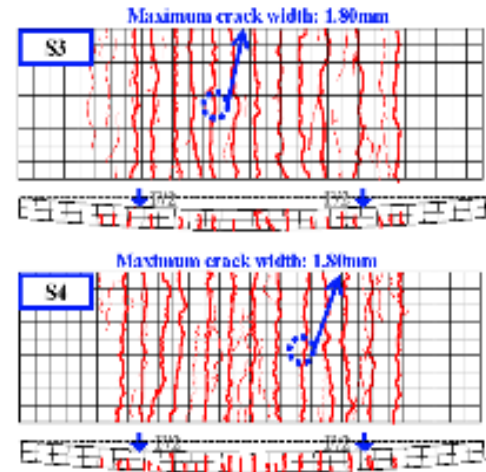
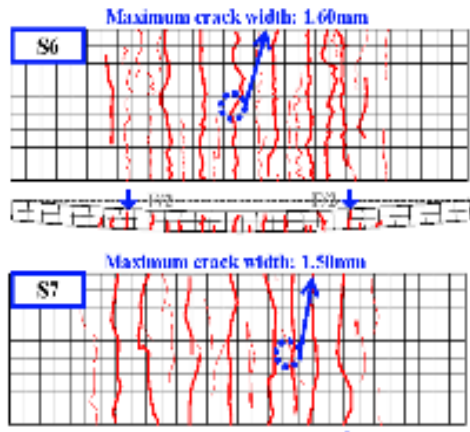

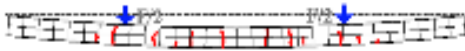

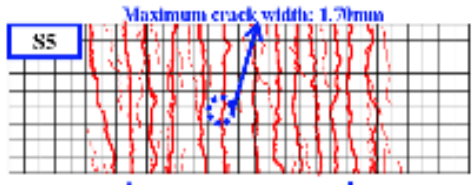

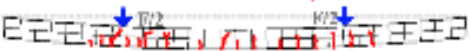

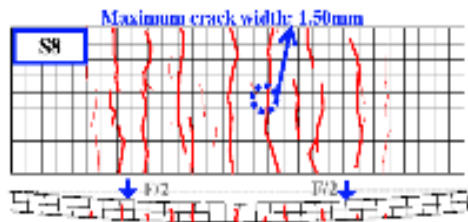

Figure 7. Typical failure characteristics and damage patterns of specimens

Table 4. Failure characteristics of the specimens

\begin{tabular}{cc}
\hline No. & Failure characteristics \\
\hline S1 & Both maximum crack width and midspan deflection exceed prescribed limits \\
S2 & Both maximum crack width and midspan deflection exceed prescribed limits \\
S3 & Both maximum crack width and midspan deflection exceed prescribed limits, at same time, load-bearing steel bar strain exceed 0.01 \\
S4 & Crack width exceed prescribed limits and load-bearing reinforcements strain exceed 0.01 \\
S5 & Crack width exceed prescribed limits and load-bearing reinforcements strain exceed 0.01 \\
S6 & Crack width exceed prescribed limits and load-bearing reinforcements strain exceed 0.01 \\
S7 & Both maximum crack width and midspan deflection exceed prescribed limits \\
S8 & Both maximum crack width and midspan deflection exceed prescribed limits \\
\hline
\end{tabular}

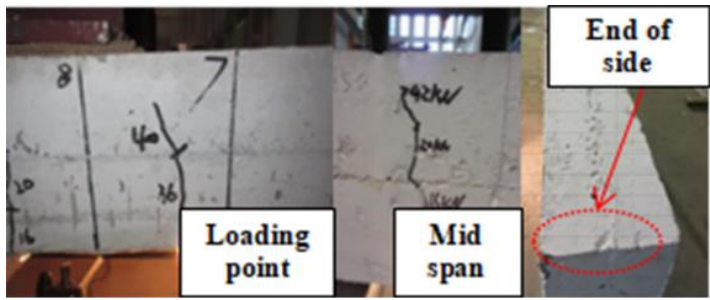

Figure 8. Side crack of S1

(ii) Comparison between the specimens with different materials: It can be seen from Figure 6 that S6 S8 had the fewest cracks on the bottom slab among all specimens, followed by $\mathrm{S} 3 \sim \mathrm{S} 5$. By contrast, $\mathrm{S} 1 \sim \mathrm{S} 2$ had the most and widest cracks on the bottom slab. The obvious advantage of S3 S8 is attributable to the steel fibres randomly distributed in concrete. These fibres enhanced the tensile/crack resistance of the matrix and hindered the crack propagation in the concrete. With the increase of the load, a small amount of fibres was pulled out from the tensile zone of the specimens [26]. These results agree well with the previous studies [27, $28]$, which hold that the addition of steel fibres and recycled aggregates can improve the mechanical strength and slow down the fracturing of concrete.

(iii) Comparison between the specimens with different shapes: Throughout the loading process, our specimens neither exhibited any adhesion failure at the interface between the bottom panel and the concrete topping, nor separation between 
the two components (otherwise, horizontal cracks may appear along the interface). This means all CCS shapes, including rough surface, rectangular-rib, cross-rib, bar truss and bar truss with rectangular-rib, ensure the good coordination between the base plate and the concrete topping, such that the CCS acts as a whole under external load. This conclusion is consistent with References [29, 30].

\subsection{Load-deflection curves}

The midspan load-deflection curves of our specimens were plotted against the mean measured span displacements (Figure 9). The ductility index [31], i.e. the ratio of the ultimate deflection to the deflection at the yielding of load-bearing bars, is shown in Table 5.

(i) Different phases of the loading process: The specimens shared a similar curve shape. The load-deflection curves were approximately straight lines at the beginning of loading. At this time, the specimens boasted a strong stiffness and a small deflection. With the growth of the load, the specimens became less stiff due to the crack formation and widening in the bottom plate and the yielding of the longitudinal load-bearing bars.

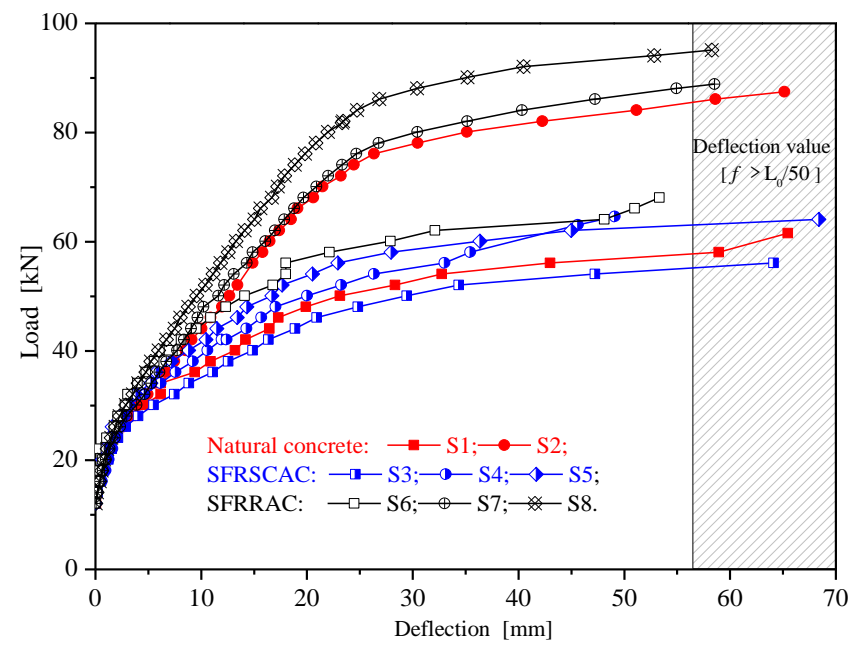

Figure 9. Specimens of load-deflection curves at mid-span

Table 5. Ductility of the specimens

\begin{tabular}{cccccc}
\hline No. & Yield load / $\mathbf{k N}$ & Ultimate load / $\mathbf{k N}$ & Displacement at yield load / $\mathbf{~ m m}$ & Displacement at ultimate load/ mm & Ductility factor \\
\hline S1 & 51.00 & 61.60 & 23.12 & 65.45 & 2.83 \\
S2 & 64.10 & 87.45 & 17.37 & 65.14 & 3.75 \\
S3 & 39.10 & 56.10 & 14.87 & 64.11 & 4.31 \\
S4 & 47.20 & 64.60 & 17.02 & 49.10 & 6.80 \\
S5 & 44.10 & 64.10 & 11.46 & 53.33 & 5.97 \\
S6 & 50.80 & 68.10 & 14.11 & 58.52 & 3.78 \\
S7 & 72.10 & 88.90 & 22.00 & 58.27 & 2.66 \\
S8 & 80.10 & 95.10 & 21.98 & & \\
\hline
\end{tabular}

(ii) Comparison between the specimens with different materials: In general, S6 S8 had the least deflection and highest bearing capacity under the same load, while S3 S5 had the greatest deflection and weakest bearing capacity. Of course, a small amount of steel fibres was pulled out from the tensile zone of the concrete as the load continued to grow in the elastic-plastic phase. Compared with S1 and S2, S3 S8 featured a small slope of their load-deflection curves, owing to the rapid development of cracking and deflection. These results were the same as those of Zhang and Pei [32].

(iii) Comparison between the specimens with different shapes: In the elastic phase, the specimens bear resemblances in the development of flexural damages. In the elastic-plastic phase, however, obvious differences emerged among the loaddeflection curves of specimens with different shapes, with the increase of load and propagation of cracks. Hence, the shape of the bottom panel has an impact on the specimen stiffness. Compared with other specimens, S2, S7 and S8 were slow in the development of deflection, indicating that composite slab with trussed bars can inhibit cracking, reduce midspan deflection and improve the specimen stiffness. Thus, it is not surprising that S8 had the lowest deflection and the highest stiffness and bearing capacity. This further testifies that truss reinforcement is a way to enhance concrete stiffness. On the contrary, the stiffness of S3 was significantly decreased, with the plunge in curve slope and upsurge of deflection. As the load-deflection curve deviated to the side of the neutral axis, the bearing capacity of this specimen no longer increased. In terms of ductility index, S2 was 32.51\% higher than S1, S5 was $107.29 \%$ higher than S4, S5 was $38.51 \%$ higher than S3, S6 is $42.11 \%$ higher than S7, and S6 is $42.64 \%$ higher than S8.
It can be seen that the shape of the bottom plate had a certain effect on the ductility of the specimen. By the degree of influence, the different shapes can be ranked as crossrib $>$ rough surface $>$ rectangular-rib $>$ bar truss $>$ bar truss with rectangular-rib. These results were the same as those of Cao et al. [33].

\subsection{Load-bar strain curves}

The midspan load-strain curves of the load-bearing bars of our specimens are displayed in Figure 10(a). The following trends can be observed from these curves.

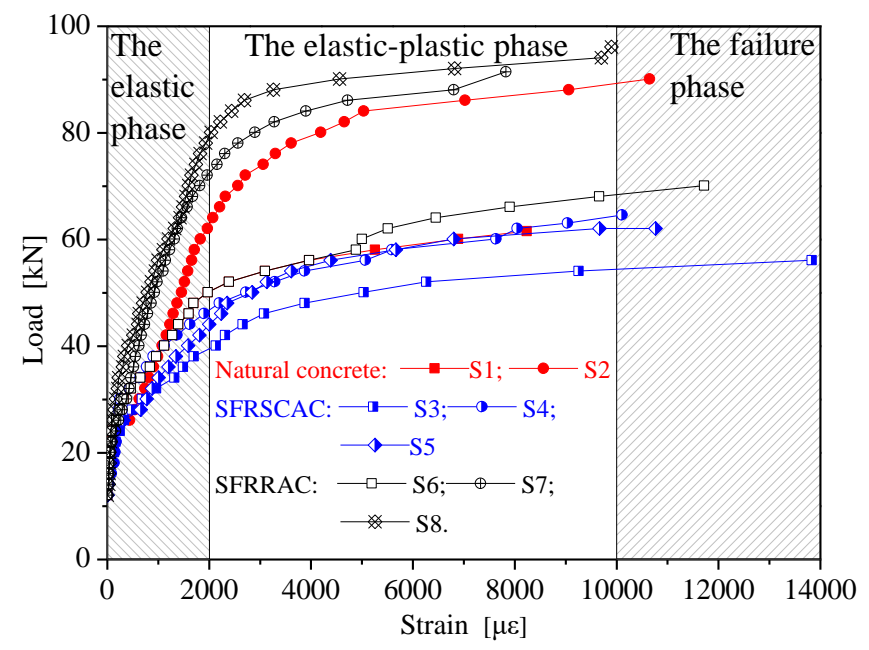

(a) Longitudinal load-bearing reinforcements 


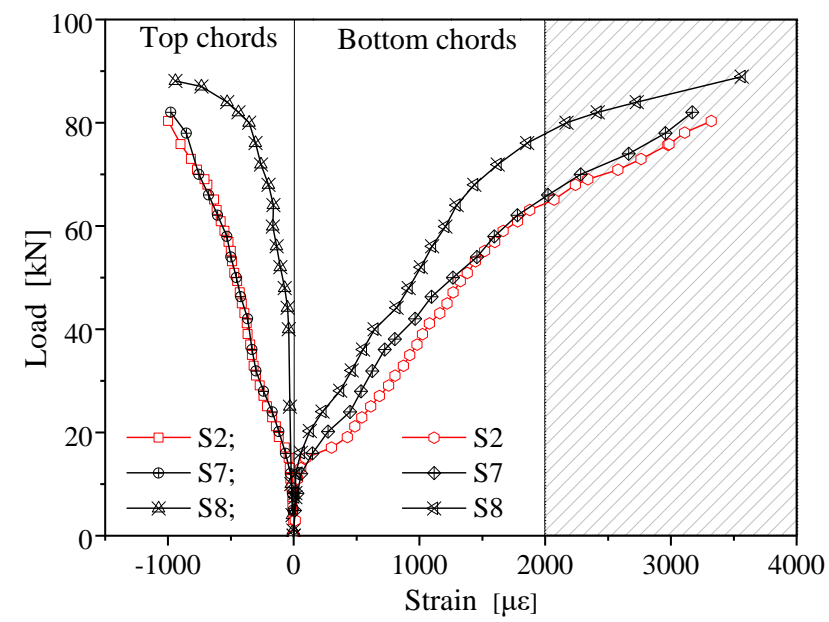

(b) Top chords/ bottom chords

Figure 10. Specimens of load-strain relationship at mid-span of longitudinal load-bearing reinforcements

(i) Different phases of the loading process: For all eight specimens, each load-bar strain curve consists of three segments: the straight segment before concrete cracking, the curved segment from cracking to bar yielding, and the smooth segment from bar yielding to the ultimate state.

(ii) Comparison between the specimens with different materials: After concrete cracking, a distinct turning point appeared on the load-bar strain curves of S1 and S2, indicating that the tensile stress at the crack in the tensile zone was completely borne by the longitudinal tensile bars. By contrast, there was no significant turning point on the curves of S3 S4, because the steel fibres carried part of the tensile stress at the crack. However, the curves of all specimens were flattened after the yielding of the bars, as the steel fibres in the tensile zone were gradually pulled out of the matrix. This trend can be explained as follows: when the matrix started to crack, the steel fibre-reinforced matrix was not destroyed at once; instead, the bearing capacity continued to grow with the stable expansion of the cracks. The steel fibres held the cracks together so that the concrete on both sides of the crack could withstand the external load. Nevertheless, the fibres were pulled out and even pulled off when the load increased to the ultimate tensile strength of SFRSCAC and SFRRAC [34].

(iii) Comparison between the specimens with different shapes: Despite the yielding in the failure phase, the longitudinal load-bearing bars of S2, S7 and S8 had a much smaller strain than those of the other specimens. The reason lies in the fact that the load on the longitudinal load-baring bars at the bottom of the cracked specimens was partially carried by the top/bottom chords and web members (Figure 10(b)).

\subsection{Concrete strain curves}

\subsubsection{Load-compressive strain curves}

The midspan load-strain curves of the compressive zone in the concrete topping were plotted according to the values captured by the strain gages (Figure 11(a)).

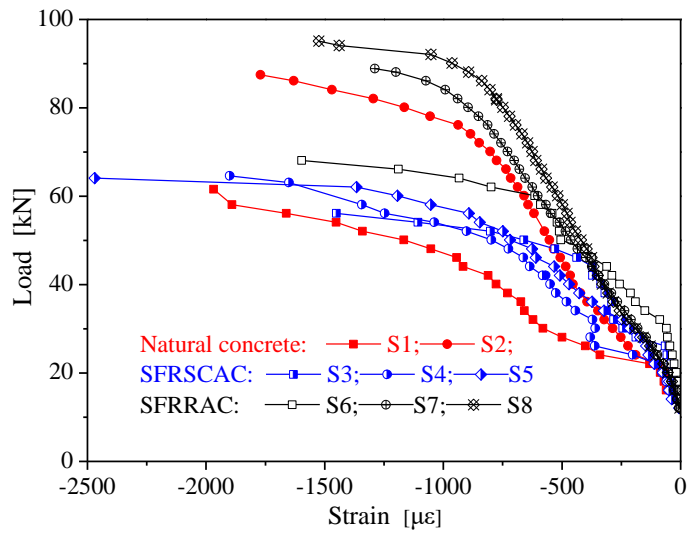

(a) Compressive zone in the concrete topping
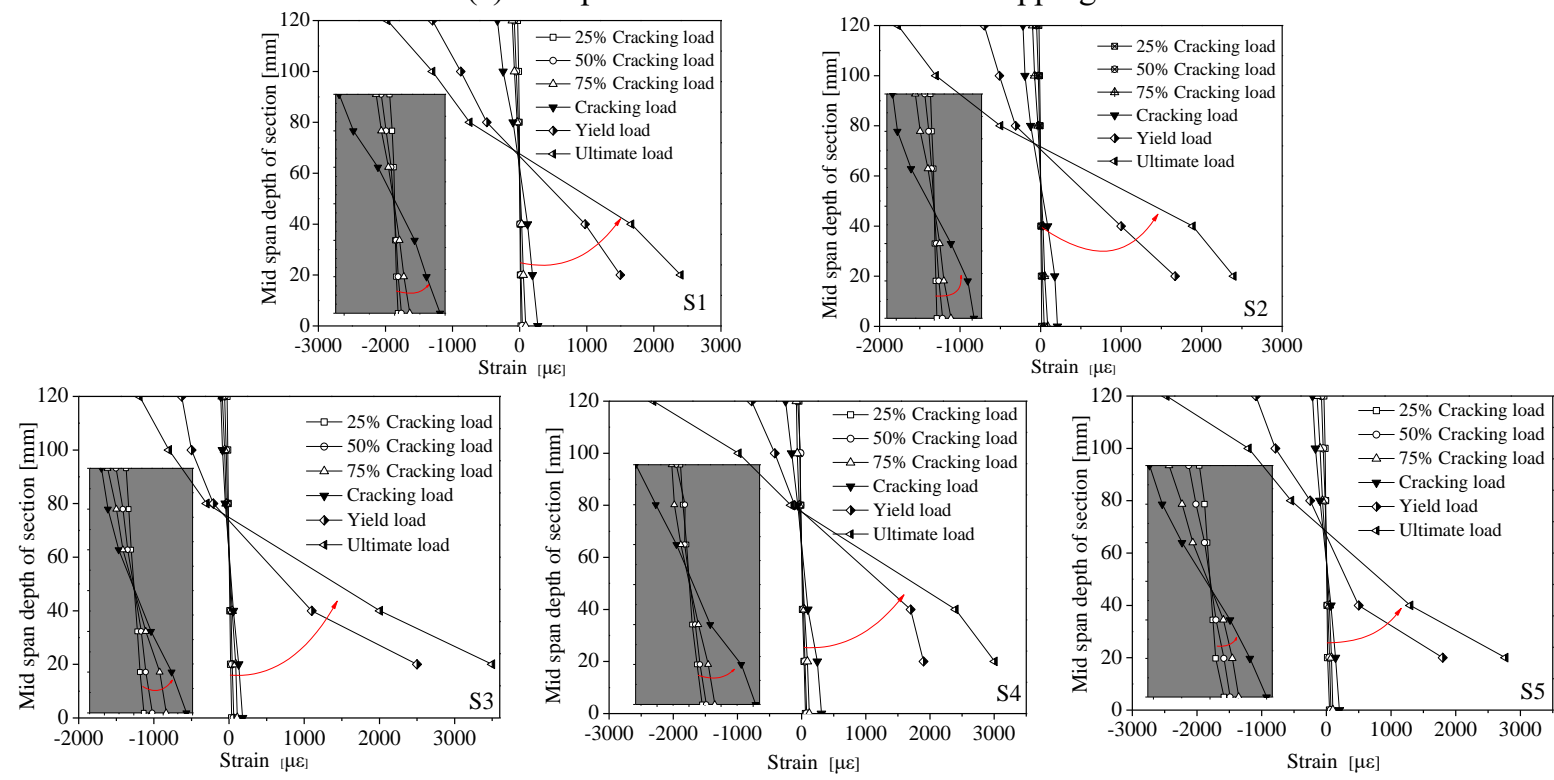

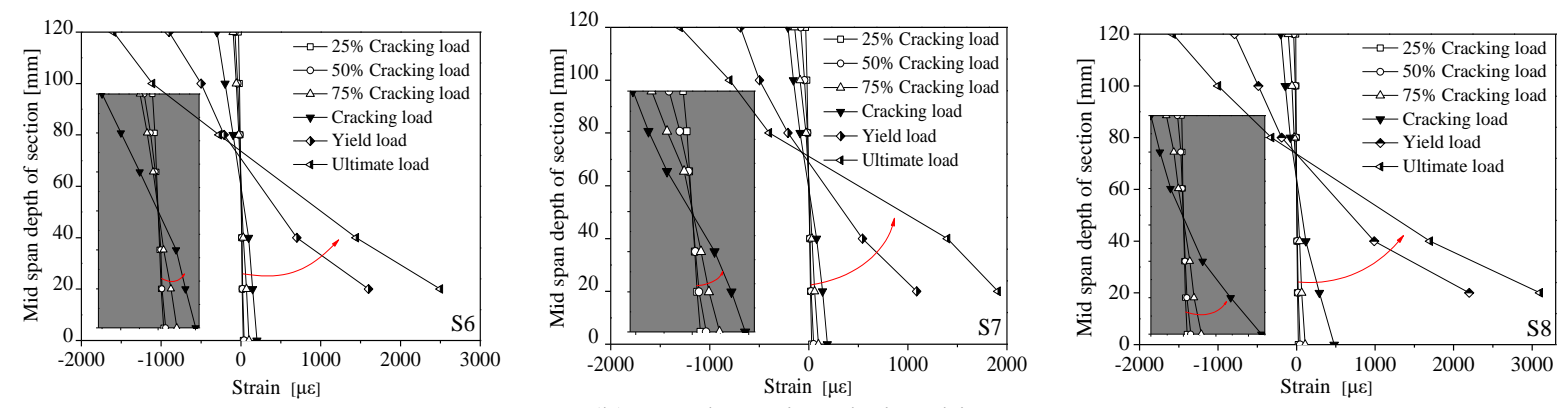

(b) Depth-strain relationship

Figure 11. Midspan load-strain curves of concrete

(i) Comparison between the specimens with different materials: The eight specimens shared similar loadcompressive strain curves. No concrete in the compressive zone was crushed at the end of loading.

(ii) Comparison between the specimens with different shapes: The curves of S2, S7 and S8 increased linearly until the failure of the specimens, while those of the other specimens exhibited a plastic state and gradually flattened out. This is because the top chords and web members of the said three specimens carried part of the strain increment of the concrete topping.

\subsubsection{Strain-depth relationship}

The strain distribution along the mid-span height was plotted according to the concrete strain values at different section heights in the side spans of the specimens in the elastic phase (Figure 11(b)).

(i) Comparison between the specimens with different materials: In the elastic phase, the cross-section mid-span strain was basically linearly correlated with the height. With the increase in external load, the neutral axis continued to move upwards. Despite a few inflection points, the straindepth curves remained proportional to the distance from the neutral axis, which conforms to the flat section assumption.

(ii) Comparison between the specimens with different shapes: Under the same load, the cross-rib specimen had the lowest interface position and the tallest compressive zone, followed by the rectangular-rib specimen. The results show that the shape of the bottom plate has a certain influence on the neutral axis.

\section{FLEXURAL CAPACITY ANALYSIS}

\subsection{Cracking moment}

\subsubsection{Basic assumptions}

For simplicity, the following assumptions were put forward to calculate the cracking moment of the specimens:

(i) The bending process of all specimens satisfies the flat section assumption.

(ii) The shape effect of the bottom panel is taken into account: The impact of top/bottom chords of bar truss on cross-section inertia moment is considered for $\mathrm{S} 2$ and $\mathrm{S} 7$; The impact of rectangular/cross-rib on cross-section inertia moment is considered for S1 and S4 S6; The impact of top/ bottom chords of bar truss and that of rectangular-rib on crosssection inertia moment is considered for S8.

(iii) The material effect of the bottom panel is considered through the calculation of the elastic modulus ratio of the bottom panel to the concrete topping.

\subsubsection{Calculation method}

Based on the above assumptions, a calculation model was set up for the cracking moment [35] (Figure 12).

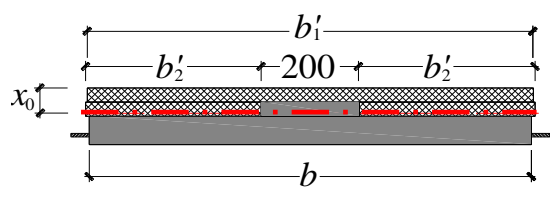

(a) $\mathrm{S} 1$

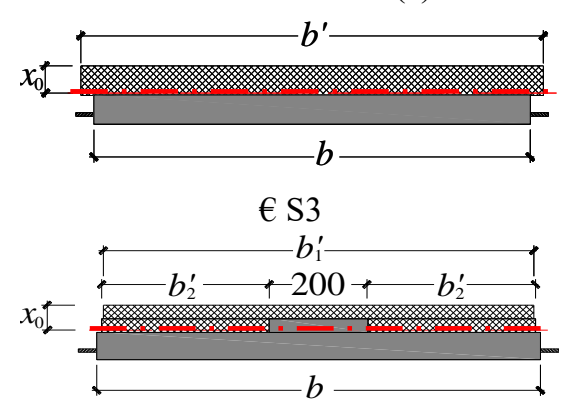

(f) S6

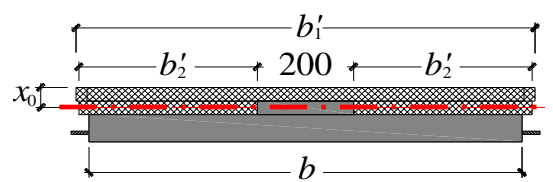

(d) S4

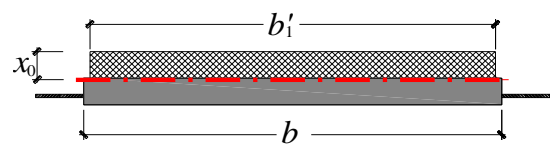

(g) $\mathrm{S} 7$

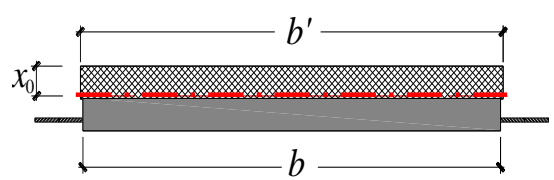

(b) S2

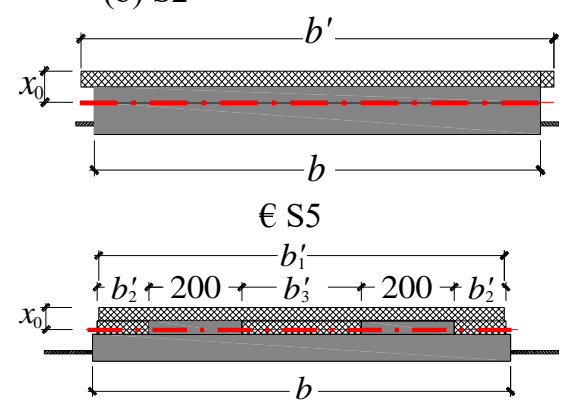

(h) $\mathrm{S} 8$

Figure 12. Cracking moment calculation model

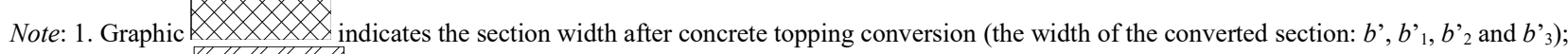
2. Graphic indicates the section after bar conversion. 
According to the Chinese code (GB 50010-2010), the cracking moment $\left(M_{\mathrm{cr}}\right)$ of S1 and S2 can be calculated by the following formula:

$$
\begin{gathered}
M_{\mathrm{cr}}=\gamma f_{\mathrm{tk}} W_{0} \\
\gamma=\left(0.7+\frac{120}{h}\right) \gamma_{\mathrm{m}} \\
W_{0}=\frac{I_{0}}{h-x_{0}}
\end{gathered}
$$

where, $\gamma_{\mathrm{m}}$ basic value of the cross-section resistance coefficient of moment plasticity (the value is 1.55); $\gamma$ is the cross-section resistance coefficient of moment plasticity; $f_{\mathrm{tk}}$ is the standard value of axial tensile strength of concrete (the test value); $W_{0}$ is the resistance moment of drawing edge cross-section; $h$ is height of cross-section; $x_{0}$ is height of compress zone.

The previous analysis shows that the tensile zone in $\mathrm{S} 3 \sim \mathrm{S} 8$ is reinforced by the steel fibres. According to the Chinese specification "Technical specification for fibre reinforced concrete structures [36] and Technical specification for the application of recycled aggregate [37]", the cracking moment $\left(M_{\mathrm{fcr}}\right)$ of these six specimens can be obtained by the following formula:

$$
M_{\mathrm{fcr}}=\gamma\left(1+\alpha_{\mathrm{t}} \lambda_{\mathrm{t}}\right) f_{\mathrm{tk}} W_{0}
$$

Gao and Liu [38] studied show that for natural concrete, the initial crack load is the tensile strength of the material, but for the steel fiber concrete, the crack strain is only the tensile peak strain of the matrix concrete. Moreover, the ultimate tensile strength of the steel fiber concrete is generally highest than its initial crack load. This is because the steel fiber can be effectively organized and the micro cracks are unstable and expanded, and the fiber itself can bear some pulling force. Therefore, the value of $f_{\mathrm{tk}}$ in ours calculation was measured by the splitting tensile strength of matrix concrete in the 1.3 section. $\alpha_{t}$ is influence coefficient of steel fiber on tensile strength of materials (the value is 0.42 ) [36]; $\lambda_{t}$ is steel fiber content characteristic value (its values and formula were detailed in Chinese specification; the value and meaning of both $\gamma$ and $W_{0}$ is the same as in formulas (3) (4).

Table 6 compares the calculated cracking moments $\left(M_{\mathrm{cr}, \mathrm{c}}\right.$ or $\left.M_{\text {frr, }}\right)$ with the measured cracking moments $\left(M_{\mathrm{cr}, \mathrm{t}}\right)$.

(i) General condition: The error between calculated and measured cracking moments was within $10 \%$ for all specimens except S5.
Table 6. Cracking moments

\begin{tabular}{cccc}
\hline No. & $\boldsymbol{M}_{\mathbf{c r}, \mathbf{c}}\left(\boldsymbol{M}_{\text {fcr,c) }} / \mathbf{k N} . \mathbf{m}\right.$ & $\boldsymbol{M}_{\text {cr, } \mathbf{t}} / \mathbf{k N . m}$ & Relative error/ $\%$ \\
\hline S1 & 7.98 & 8.20 & 2.67 \\
S2 & 8.11 & 8.91 & 9.86 \\
S3 & 7.51 & 7.63 & 1.60 \\
S4 & 7.68 & 8.12 & 5.73 \\
S5 & 8.35 & 10.47 & 25.39 \\
S6 & 8.20 & 8.34 & 1.71 \\
S7 & 9.41 & 10.33 & 9.78 \\
S8 & 9.50 & 10.33 & 8.74 \\
\hline
\end{tabular}

(ii) Comparison between the specimens with different materials: The calculated cracking moments were consistent with the test phenomena: the specimen with SFRRAC base plate had the highest cracking moment, while the specimen with SFRSCAC base plate had a small cracking moment. The results validate the feasibility of the calculation model.

(iii) Comparison between the specimens with different shapes: The rough surface specimen boasted the smallest error, and the bar truss with rectangular rib specimen achieved a smaller-than-10\% error, which is acceptable. However, the cross-ribbed specimen had a large error, requiring further analysis on the simplification of the calculation model.

\subsection{Ultimate bending moment}

\subsubsection{Basic assumptions}

For simplicity, the following assumptions were put forward to calculate the ultimate bending moment of the specimens:

(i) The contribution of top/bottom chords to the ultimate bending moment is considered for S2, S7 and S8.

(ii) The contribution of steel fibres to flexural bearing capacity is considered for $\mathrm{S} 3 \sim \mathrm{S} 8$.

(iii) The impact of distributed bars $(8 @ 200)$ is considered due to their role in stress bearing.

\subsubsection{Calculation method}

According to the Chinese code (GB 50010-2010), the cracking moment of $\mathrm{S} 1$ and $\mathrm{S} 2$ can be calculated by the following formulas (Figure 13):

$$
\begin{gathered}
M_{\mathrm{u}}=f_{\mathrm{y}} A_{s}\left(h_{0}-x / 2\right)-f_{\mathrm{y}}{ }^{\prime} A_{s}{ }^{\prime} a_{s}{ }^{\prime} \\
\alpha_{1} f_{\mathrm{c}} b x+f_{\mathrm{y}}{ }^{\prime} A_{s}{ }^{\prime}=f_{\mathrm{y}} A_{\mathrm{s}}
\end{gathered}
$$

According to the Chinese specification (CSCE 38:2004; JGJ/ T 240-2011), the cracking moment of S3 S8 can be obtained by the following formulas (Figure 13):

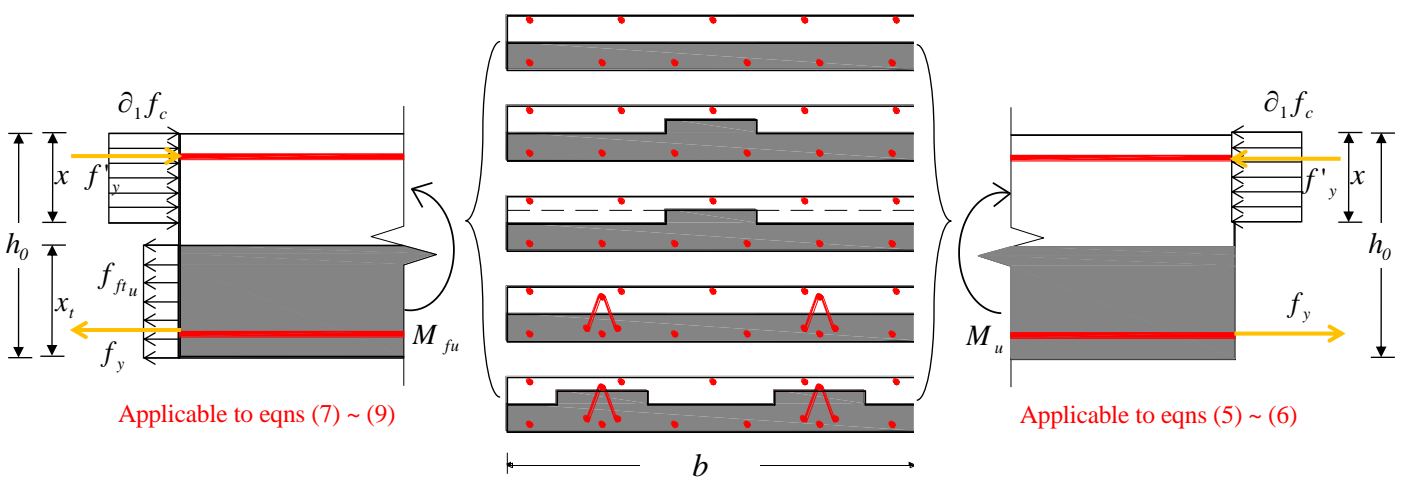

Figure 13. Ultimate bending moment calculation model 


$$
\begin{gathered}
M_{\mathrm{fu}}=f_{\mathrm{y}} A_{s}\left(h_{0}-x / 2\right)+f_{\mathrm{ftu}} b x_{\mathrm{t}}\left(h-x / 2-x_{\mathrm{t}} / 2\right)-f_{\mathrm{y}}{ }^{\prime} A_{s}{ }^{\prime} a_{s}{ }^{\prime} \\
\alpha_{1} f_{\mathrm{c}} b x+f_{\mathrm{y}}{ }^{\prime} A_{s}{ }^{\prime}=f_{\mathrm{y}} A_{\mathrm{s}}+f_{\mathrm{ftu}} b x_{\mathrm{t}} \\
f_{\mathrm{ftu}}=f_{\mathrm{t}} \beta_{\mathrm{tu}} \lambda_{\mathrm{f}}
\end{gathered}
$$

where, $f_{\mathrm{y}}$ is the longitudinal load-bearing bars tensile strength (the test value); $f_{\mathrm{y}}^{\prime}$ is distributed bars tensile strength (the test value); $f_{\mathrm{c}}$ is design value of axial compressive strength (the test value); $x$ is height of concrete compression zone; $x_{\mathrm{t}}$ is the height of the equivalent rectangular stress in tensile zone (the value is $0.06 \mathrm{~mm})^{36}$; it is note that $f_{\mathrm{ftu}}$, which is the tensile strength of equivalent rectangle stress pattern of SFRSCAC or SFRRAC in tension zone at ultimate capacity state, and this value was applied calculation by formulas (10); The value and meaning of both $f_{\mathrm{t}}$ and $\lambda_{t}$ is the same as in formulas (5); $\beta_{t u}$ is influence coefficient of steel fibre on tensile strength of tensile zone in section (the value is 1.30$)^{36}$.

Table 7. Ultimate bending moments

\begin{tabular}{cccc}
\hline No. & $\boldsymbol{M}_{\mathbf{u}, \mathbf{c}}\left(\boldsymbol{M}_{\mathbf{f u}, \mathbf{c}}\right) / \mathbf{k N} \mathbf{~ m}$ & $\boldsymbol{M}_{\mathbf{u}, \mathbf{t}} / \mathbf{k N} . \mathbf{m}$ & Relative error/ $\%$ \\
\hline S1 & 20.98 & 21.76 & 4.81 \\
S2 & 26.67 & 30.77 & 15.49 \\
S3 & 20.40 & 18.99 & -6.91 \\
S4 & 20.40 & 19.87 & -2.60 \\
S5 & 20.40 & 21.83 & 6.55 \\
S6 & 21.91 & 22.08 & 7.01 \\
S7 & 26.78 & 31.60 & 17.44 \\
S8 & 26.78 & 34.56 & 29.05 \\
\hline
\end{tabular}

Table 7 compares the calculated ultimate bending moments $\left(M_{\mathrm{u}, \mathrm{c}}\right.$ or $\left.M_{\mathrm{fu}, \mathrm{c}}\right)$ with the measured ultimate bending moments $\left(M_{\mathrm{u}, \mathrm{t}}\right)$.

(i) Comparison between the specimens with different materials: The calculated ultimate bending moments were consistent with the test phenomena: the specimen with SFRRAC base plate had the highest ultimate bending moment, while the specimen with SFRSCAC base plate had a small ultimate bending moment.

(ii) Comparison between the specimens with different shapes: The calculated ultimate bending moments of rough surface, rectangular-rib and cross-rib specimens agreed well with the measured results, with errors within $10 \%$. However, the bar truss with rectangular rib specimen had a large error between the calculated and measured ultimate bending moments, indicating that its calculation model should be further studied.

\section{CONCLUSIONS}

This paper experimentally investigates the flexural performance of CCSs with different materials and shapes under static load. Such indices as failure modes, loaddeflection curves, load-rebar strain curves, load-concrete strain curves and strain-depth relationship were analysed in details. Finally, the calculation methods were proposed for the cracking and ultimate bending moments of the CCS. Through the research, the following conclusions were derived:

(i) Under the vertical load, the eight specimens shared similar flexural behaviours and all underwent the elastic phase, elastic-plastic phase and failure phase. Some obvious features were observed before failure, including the continued development of cracks and deflections and the progressive ductile failure of tensile bars.

(ii) The crack resistance of both SFRSCAC and SFRRAC were greatly improved through the addition of steel fibres. These fibres overcame the poor fracture resistance and low ductility, and prevent the brittle fracture of these specimens. In addition, the SFRRAC specimen had high ultimate bending moment and cracking moment, and thus small maximum crack width and deflection.

(iii) The shape of the bottom plate has a major impact on the flexural performance of the CCS, especially in the elasticplastic phase and the failure phase. The impact is particular obvious in the bar truss specimen, as evidenced by the boost of stiffness and bearing capacity. By the ultimate bending moment, the specimens can be ranked as bar truss with rectangular-rib $>$ bar truss $>$ cross-rib $>$ rectangular-rib $>$ rough surface. The ductility index is also influenced by the shape of the bottom plate.

(iv) The effect of the bottom plate should be considered in the calculation of the cracking moment, and the contribution of steel fibres to the tensile zone should be taken into account for the calculation of ultimate bending moments of the CCSs fabricated by SFRSCAC or SFRRAC.

\section{REFERENCES}

[1] Mohamad, M.I., Nekooie, M.A., Taherkhani, R., Saleh, A.L., Mansur, S.A. (2012). Exploring the potential of using industrialized building system for floating urbanization by SWOT analysis. Journal of Applied Sciences (Faisalabad), 12(5): 486-491.

[2] Cao, X., Li, X., Zhu, Y., Zhang, Z. (2015). A comparative study of environmental performance between prefabricated and traditional residential buildings in China. Journal of Cleaner Production, 109: 131-143. https://doi.org/10.1016/j.jclepro.2015.04.120

[3] Kim, D. (2008). Preliminary Life Cycle Analysis of Modular and Conventional Housing in Benton Harbor, MI (Doctoral dissertation). University of Michigan, Ann Arbor. http://hdl.handle.net/2027.42/58212

[4] Nadim, W., Goulding, J.S. (2011). Offsite production: A model for building down barriers. Engineering, Construction and Architectural Management, 18(1): 82101. https://doi.org/10.1108/09699981111098702

[5] Kamar, K.A.M., Hamid, Z.A. (2011). Supply chain strategy for contractor in adopting industrialized building system (IBS). Australian Journal of Basic and Applied Sciences, 5(12): 2552-2557.

[6] Yee, A.A., Eng, P.H.D. (2001). Structural and economic benefits of precast/prestressed concrete construction. PCI Journal, 46(4): 34-43. https://doi.org/10.15554/pcij.07012001.34.42

[7] Institute, P.C. (2004). PCI design handbook: precast and prestressed concrete ( $6^{\#}$ Edition)., PCI, Chicago, IL, USA.

[8] Daniels, B.J., Crisinel, M. (1993). Composite slab behavior and strength analysis. Part I: Calculation procedure. Journal of Structural Engineering, 119(1): 1635 . 9445(1993)119:1(16)

[9] Daniels, B.J., Crisinel, M. (1993). Composite slab behavior and strength analysis. Part II: Comparisons with test results and parametric analysis. Journal of Structural Engineering,

119(1):

36-49. 
https://doi.org/10.1061/(ASCE)0733-

9445(1993)119:1(36)

[10] Girhammar, U.A., Pajari, M. (2008). Tests and analysis on shear strength of composite slabs of hollow core units and concrete topping. Construction and Building Materials, 22(8): 1708-1722. https://doi.org/10.1016/j.conbuildmat.2007.05.013

[11] Thanoon, W.A., Yardim, Y., Jaafar, M.S., Noorzaei, J. (2010). Structural behaviour of ferrocement-brick composite floor slab panel. Construction and Building Materials, $24(11)$ 2 $224-2230$ https://doi.org/10.1016/j.conbuildmat.2010.04.034

[12] Zhang, J., Yao, Y., Zhou, X., Yang, Y., Wang, Y. (2013). Failure mode and ultimate bearing capacity of precast ribbed panels used for concrete composite slabs. Advances in Structural Engineering, 16(12): 2005-2017. https://doi.org/10.1260/1369-4332.16.12.2005

[13] Mansour, F.R., Bakar, S.A., Ibrahim, I.S., Marsono, A.K., Marabi, B. (2015). Flexural performance of a precast concrete slab with steel fiber concrete topping. Construction and Building Materials, 75: 112-120. https://doi.org/10.1016/j.conbuildmat.2014.09.112

[14] Mohamad, N., Khalifa, H., Samad, A.A.A., Mendis, P., Goh, W.I. (2016). Structural performance of recycled aggregate in CSP slab subjected to flexure load. Construction and Building Materials, 115: 669-680. https://doi.org/10.1016/j.conbuildmat.2016.04.086

[15] Tang, Z., Zha, X., Zu, D. (2016). Bending properties of steel faced sandwich composite panels with phenolic foam cores. Journal of Reinforced Plastics and Composites, $\quad 35(10)$ : 834-852. https://doi.org/10.1177/0731684416631839

[16] Kim, S.W., Yun, H.D. (2013). Influence of recycled coarse aggregates on the bond behavior of deformed bars in concrete. Engineering Structures, 48: 133-143. https://doi.org/10.1016/j.engstruct.2012.10.009

[17] Folino, P., Xargay, H. (2014). Recycled aggregate concrete-Mechanical behavior under uniaxial and triaxial compression. Construction and Building Materials, 56: 21-31. https://doi.org/10.1016/j.conbuildmat.2014.01.073

[18] Li, B., Huang, W., Li, C., Dong, K. (2017). Study on damage constitutive model of steel fiber recycled brick aggregate concrete. Journal of Huazhong University of Science and Technology (Natural Science), 45(1): 17-23. https://doi.org/10.13245/j.hust.170104

[19] Huang, W., Li, B., Song, L., Xiong, Y. (2017). Orthogonal experiment research on the strength of fiber reinforced silt ceramist concrete. Journal of XiZ an University of Architecture \& Technology (Natural Science), 49(1): 22-28. https://doi.org/10.15986/j.10067930.2017.01.004

[20] GB 50011, 2010 (2015). Code for Seismic Design of Buildings. China Architecture \& Building Press, Beijing, China.

[21] JGJ 1-2014. (2014). Technical Specification for Precast Concrete Structures. China Architecture \& Building Press, Beijing, China.

[22] Xiong, Y.K. (2015). Studies on basic mechanics of fiber reinforced ceramsite concrete ( $\mathrm{PhD}$ thesis). Xi'an University of Architecture and Technology, Xi' an, China.

[23] Dong, K.L. (2015). Research on Basic Mechanical Performance of Fiber recycled aggregate concrete $(\mathrm{PhD}$ thesis). Xi' an University of Architecture and Technology,
Xi'an, China.

[24] GB/T 50152-2012. (2012). Standard for Test Method of Concrete Structures. China Architecture \& Building Press, Beijing, China.

[25] Feng, P., Cheng, S., Bai, Y., Ye, L. (2015). Mechanical behavior of concrete-filled square steel tube with FRPconfined concrete core subjected to axial compression. Composite Structures, 123: 312-324. https://doi.org/10.1016/j.compstruct.2014.12.053

[26] Naaman, A.E., Shar, S.R. (1976). Pull-out mechanism in steel fibre-reinforced concrete. Journal of the Structural Division, 102: 1537-1548. https://doi.org/10.1016/00221694(76)90061-5

[27] Kim, Y.C., Baek, S.M., Kim, W.S., Kang, T.H., Kwak, Y.K. (2014). An experimental study on flexural behavior of steel fiber reinforced concrete beams using recycled coarse aggregates. Journal of the Architectural Institute of Korea Structure \& Construction, 30(3): 39-48. https://doi.org/10.5659/JAIK_SC.2014.30.3.039

[28] Carneiro, J.A., Lima, P.R.L., Leite, M.B., Toledo Filho, R.D. (2014). Compressive stress-strain behavior of steel fiber reinforced-recycled aggregate concrete. Cement and Concrete Composites, 46: 65-72. https://doi.org/10.1016/j.cemconcomp.2013.11.006

[29] Kumar, N.V., Ramirez, J.A. (1996). Interface horizontal shear strength in composite decks with precast concrete panels. PCI Journal, 41(2): 42-55.

[30] Jiang, H., Fang, Z., Liu, A., Li, Y., Feng, J. (2016). Interface shear behavior between high-strength precast girders and lightweight cast-in-place slabs. Construction and Building Materials, 128: 449-460. https://doi.org/10.1016/j.conbuildmat.2016.10.088

[31] Mansour, F.R., Bakar, S.A., Ibrahim, I.S., Marsono, A. K., Marabi, B. (2015). Flexural performance of a precast concrete slab with steel fiber concrete topping. Construction and Building Materials, 75: 112-120. https://doi.org/10.1016/j.conbuildmat.2014.09.112

[32] Zhang, H.L., Pei, C.C. (2017). Flexural properties of steel fiber types and reinforcement ratio for high-strength recycled concrete beams. Advances in Structural Engineering, 20(10): 1512-1522. https://doi.org/10.1177/1369433216683196

[33] Cao, W.L., Zhang, J., Dong, H.Y. (2014). Experimental research on flexural performance of high strength recycled aggregate concrete slabs with steel bar truss. Journal of Building Structures, 35(10): 31-38. https://doi.org 10.14006/j.jzjgxb.2014.10.004

[34] Özcan, D.M., Bayraktar, A., Şahin, A., Haktanir, T., Türker, T. (2009). Experimental and finite element analysis on the steel fiber-reinforced concrete (SFRC) beams ultimate behavior. Construction and Building Materials, 23(2): 1064-1077. https://doi.org/10.1016/j.conbuildmat.2008.05.010

[35] Тимошенко, С.П. (1970). Theory of Elasticity (3\# Edition) Higher Education Press, Beijing, China.

[36] CECS 38 (2004). Technical Specification for Fiber Reinforced Concrete Structures. Planning Press, Beijing, China.

[37] JGJ/T 240 (2011). Technical Specification for Lightweight Aggregate Concrete Structures. China Architecture \& Building Press, Beijing, China.

[38] Gao D.Y. Liu J.X. (1994). Basic Theory of Steel Fibre Reinforced Concrete. Science and Technology of China Press, Beijing, China. 